\title{
AS IMPRESSÕES DE SENSAÇ̃̃O REPRESENTAM OS OBJETOS EXTERNOS?: \\ Considerações sobre o caráter representativo das percepções no Tratado da Natureza Humana
}

Rômulo Martins Pereira

Doutorando do Programa de pós-graduação em Filosofia (UFRJPPGF) e do Departamento de Filosofia, Comunicação e Informação (UC). Bolsista CAPES. E-mail: mp.romulo@gmail.com

\section{RESUMO}

O presente artigo objetiva primeiramente estabelecer as diferenças empreendidas por Hume, em seu Tratado da Natureza Humana, entre as percepções da mente, a saber, as impressões e as ideias. Há uma diferença qualitativa entre as percepções, ou essa diferença reside apenas no grau de força e vividez com que elas surgem na mente? Com isso, analisaremos se as impressões providas pela sensação podem representar intencionalmente os objetos externos, do mesmo modo como se considera que as ideias representam os seus objetos. Ora, se uma ideia pode representar outra ideia ou, primordialmente, uma impressão, o que, por seu turno, uma impressão de sensação pode representar? A referência a uma impressão de sensação como sendo uma impressão "de" algo significa que essa impressão está direcionada a esse algo, como ocorre no caso das ideias?

PALAVRAS-CHAVE: Percepção. Impressão. Ideia. Representação. Objeto.

\section{THE IMPRESSIONS OF SENSE REPRESENT THE EXTERNAL OBJECTS?: Considerations about the representative character of the Treaty on human nature}

\begin{abstract}
This article aims firstly to determine the diferences between the perceptions of the mind, namely, impressions and ideas, undertaken by Hume in the Treatise of Human Nature. Is there a qualitative distinction between perceptions, or their difference lies only in the degree of force and vivacity with which they arise in the mind? Thereby we examine whether the impressions provided by sensation may intentionally represent external objects, just as it is considered that the ideas represent their objects. If an idea can
\end{abstract}


represent another idea or primarily an impression, which in turn an impression of sensation may represent? The reference to an impression of sensation as an impression "of" something means that this impression is directed to that something, as in the case of ideas?

KEYWORDS: Perception. Impression. Idea. Representation. Object.

\section{INTRODUÇÃO}

Em seu Tratado da Natureza Humana, David Hume busca estabelecer uma "ciência da natureza humana" baseada em seu método experimental, a qual mostra o modo como a nossa mente opera (por exemplo, como chegamos a adquirir determinadas ideias, como chegamos a crer nelas etc.). Para essa empreitada, é comumente aceito que Hume tenha partido da "teoria das ideias": pensar, em todas as suas distintas modalidades, significa o mesmo que ter ideias imediatamente presentes à mente.

Rigorosamente, na sua versão, o termo mais genérico que se refere aos "objetos" que povoam a mente não são "ideias”, como na versão lockeana (a qual possui mais vestígios de sua herança direta), mas sim "percepções". O pressuposto essencial dessa teoria (conforme reformulada por Hume) é que, sempre que se tem um evento mental, sempre que ocorre algo na mente (seja sentido, rememorado ou refletido), isso significa o mesmo que ter percepções diante dela.

À primeira vista, o critério distintivo fundamental que nos permite reconhecer uma percepção como sendo uma impressão ou uma ideia reside no grau de força e vividez com que uma e outra surgem na mente, não obstante Hume também caracterizar uma ideia como sendo uma "imagem" menos vívida de uma impressão e essa, por sua vez, como sendo as percepções que, originalmente, aparecem na mente.

Não há dúvidas de que Hume, repetidamente, enfatiza que o critério de distinção baseado no grau de força e vividez deve ser considerado como o critério primordial. Nesse sentido, assume-se que nós podemos perceber o grau de força e vividez com que uma percepção aparece na mente e, com isso, reconhecer se essa percepção consiste em uma impressão ou uma ideia (ou ao menos que esse reconhecimento pode se dar dessa maneira em grande parte dos casos). 
Não obstante, se Hume não objetiva estabelecer uma diferença qualitativa entre nossas percepções, seria difícil compreender em que sentido a sua distinção se afastaria da de Locke. Hume introduz o termo "impressão" justamente para salientar uma distinção, que, segundo ele, a divisão de Locke (entre ideias de sensação e ideias de reflexão) não comportaria.

\section{CONSIDERAÇÕES SOBRE O CARÁTER REPRESENTATIVO DAS PERCEPÇÕES NO TRATADO DA NATUREZA HUMANA}

Ao utilizar o termo "ideia" como circunscrevendo todos os objetos de nossa mente, Locke não permite uma diferença qualitativa entre os objetos que provêm da sensação e os que provêm da reflexão. Assim, sublinhamos que não estamos de acordo com as interpretações que sugerem que a diferença entre as nossas percepções seja apenas uma diferença em relação ao grau de força e vividez ${ }^{1}$, muito embora Hume enfatize esse critério de distinção.

Esse é um ponto bastante controverso entre os intérpretes e, certamente, tem a sua origem na própria maneira como Hume formula essa diferenciação - ele enfatiza, por um lado, que as percepções se reduzem a dois gêneros distintos (descrevendo uma como sendo "original" e a outra como sendo "cópia") e, por outro, que essa diferença consiste simplesmente nos graus de força e vividez (o que sugere que esses dois gêneros são, na verdade, duas espécies de um mesmo gênero). Por seu turno, Garret (2003, p. 3) defende que Hume objetiva estabelecer tão somente uma diferença em relação ao modo como a mente sente a força e vividez de uma ou outra percepção quando nela se originam (e não uma diferença qualitativa, que residiria, supostamente, nas próprias percepções).

Embora concordemos que a diferença entre as percepções baseada no grau de força e vividez consista em uma diferença acerca do modo como a mente as sente, ao longo desse artigo, buscaremos argumentar que Hume também precisa estabelecer uma diferença qualitativa entre elas ${ }^{2}$ e que, por isso, a distinção que o filósofo estabelece em relação à sua origem causal é fundamental para a prescrição dessa diferença. É-nos bastante sugestivo que, na mesma nota

\footnotetext{
${ }^{1}$ Acerca desse ponto, além da interpretação de Garret (2006, 2008), que exporemos brevemente a seguir, referimonos também, especificamente, às interpretações de Noonan (1999, p. 60-62), Beebee (2006, p. 15) e Broughton (2006, p. 43).

${ }^{2}$ A respeito da assunção da existência de uma diferença qualitativa entre as percepções ou, mais precisamente, de um critério de divisão entre impressões e ideias que não seja apenas em relação ao grau de força e vividez, referimo-nos às seguintes interpretações: Kemp Smith (1949, p. 205-215), Stroud (1977, p. 17-35), Waxman (1994, p. 33-42), Dicker (2001, pp. 5-14), Kail (2007, p. 27-31), Allison (2008, p. 13-21) e Wright (2009, p. 6467).
} 
em que Hume sublinha que a sua divisão se diferencia da de Locke, justamente porque ele utiliza o termo "ideia" como representativo de um dos dois gêneros distintos de percepções, ele afirme o seguinte: “Quanto ao termo 'impressão', gostaria que não se o entendesse aqui como exprimindo a maneira pela qual nossas percepções vívidas são produzidas na alma, mas como exprimindo apenas as próprias percepções ...” (HUME, 2009, p. 23, grifo nosso).

Ora, se a diferença entre as percepções fosse meramente em relação ao grau de força e vividez, não haveria como garantir que o limite entre o que constitui uma impressão e o que constitui uma ideia não pudesse ser transpassado. Por consequência, se uma ideia pudesse se transformar em uma impressão mediante o aumento crescente em seu grau de força e vividez e vice-e-versa (se uma impressão pudesse se transformar em uma ideia mediante a diminuição desse grau), não seria possível que Hume estabelecesse, propriamente, o princípio de que toda ideia simples é derivada, em última instância, de uma impressão simples, pois não haveria como garantir que as impressões não foram, por sua vez, transformações de ideias ${ }^{3}$.

Em outros termos, se Hume não tivesse outro critério de divisão além daquele estabelecido acerca do modo como a mente sente o grau de força e vividez de uma percepção, um amento ou diminuição considerável nesse grau implicaria uma transformação na própria percepção. Ao contrário, Hume descreve as impressões de sensação como originando as ideias correspondentes (as "cópias" dessas impressões) e essas, por sua vez, como originando as impressões de reflexão, as quais originam outras ideias e assim por diante - e não como umas se transformando em outras.

Sobretudo, Hume admite que o limite entre uma impressão e uma ideia pode ser bastante tênue e que, por isso, a mente pode se confundir e tomar uma pela outra (seja quando uma ideia surge muito forte e vívida na mente, seja quando uma impressão ocorre de um modo fraco e apagado). Se a diferença entre elas fosse meramente uma diferença em relação ao grau de vivivacidade, não haveria possibilidade para que a mente confundisse uma pela outra, porque simplesmente as mais vívidas seriam tomadas como impressões e as menos vívidas, como

\footnotetext{
${ }^{3}$ Apesar de Locke utilizar o temo "ideia" tanto para os objetos da mente que são providos pela sensação quanto para os que são providos pela reflexão, essa transmutação não ocorreria justamente porque ele deixa bem claro qual a sua origem causal (as primeiras são causadas pela percepção dos objetos externos e as segundas, pela percepção das operações da mente).
} 
ideias ${ }^{4}$. Ao mostrar que essa confusão pode ocorrer, o filósofo parece sugerir que elas não podem, de fato, serem transformadas unicamente mediante o modo como a mente as sente.

Uma vez que as percepções derivadas diretamente da visão ou dos outros sentidos consistem nas impressões de sensação, podemos afirmar que os objetos representados pelas ideias são, em muitos casos, essas próprias impressões - excetuando os casos em que os objetos das ideias são impressões de reflexão ou outras ideias. Ora, se uma ideia pode representar outra ideia ou, primordialmente, uma impressão, o que, por seu turno, uma impressão de sensação pode representar?

Em outros termos, se uma ideia sempre parece se direcionar a um objeto, o qual, no caso, pode ser tanto uma impressão como uma outra ideia (isto é, se uma ideia é sempre uma ideia "de" ou "sobre" algo), caberia indagarmos se uma impressão também tem esse caráter (e, se tem, em que sentido ele se diferencia do caráter representativo de uma ideia). Uma resposta possível a essa pergunta seria apontar que essas impressões representam os objetos corpóreos externos dos quais temos experiência.

Mas essa afirmação, a nosso ver, ultrapassaria aquilo que podemos vislumbrar unicamente mediante nossas percepções e asseguraria uma realidade externa independentemente das mesmas, o que iria contra o seu método experimental, na parte teórica de sua filosofia, de apenas inspecionar aquilo que se passa em nossas mentes. Ao iniciar a sua investigação sobre como se constituem os nossos raciocínios concernentes a causas e efeitos, Hume enfatiza que a primeira coisa a ser explicitada deve ser a originalidade de nossas impressões de sensação, tendo em vista que todo raciocínio causal deriva de alguma impressão (ou de alguma ideia da memória, a qual, por sua vez, deriva de uma impressão de sensação).

A respeito dessa originalidade, Hume afirma:

Quanto às impressões provenientes dos sentidos, sua causa última é, em minha opinião, inteiramente inexplicável pela razão humana, e será sempre impossível decidir com certeza se elas surgem imediatamente do objeto, se são produzidas pelo poder criativo da mente, ou ainda se derivam do autor de nosso ser (HUME, 2009, 113).

A explicitação dessa questão nos parece de extrema importância uma vez que consideramos difícil compreender em que sentido uma impressão pode ser distinguida de uma ideia apenas mediante a percepção de seus distintos graus de força e vividez (principalmente se

\footnotetext{
${ }^{4}$ Cf. Kemp Smith (1949, p. 210); Waxman (1994, p. 30); Dicker (2001, p. 6); Allison (2008, p. 17).
} 
levarmos em conta que Hume reconhece que a mente pode, em dadas circunstâncias, confundir uma pela outra).

Ora, se uma ideia sempre parece se direcionar a um objeto, o qual, no caso, pode ser tanto uma impressão como uma outra ideia (isto é, se uma ideia é sempre uma ideia "de" ou "sobre" algo), caberia indagarmos se uma impressão também tem esse caráter (e, se tem, em que sentido ele se diferencia do caráter representativo de uma ideia). Em outros termos, teoricamente, podemos fazer alusão a uma impressão como sendo uma impressão "de" algo (como se essa impressão estive, intencionalmente, direcionada a esse algo)?

Em sentido amplo, corrente, podemos dizer que sim, mas acreditamos que isso apenas ocorre porque quando nos referimos a elas em nossa linguagem cotidiana, naturalmente estamos fazendo uso de ideias - com efeito, se queremos mencionar que percebemos sensivelmente algo, dizemos que tivemos uma impressão "de" algo (mas ao fazermos essa menção, o que temos, na verdade, é a ideia “de" algo na memória). Entrementes, a referência a uma impressão de sensação como sendo uma impressão "de" algo significa que essa impressão está direcionada a esse algo (como parece ocorrer no caso das ideias)?

Em primeiro lugar, consideramos que Hume buscou, primordialmente, distinguir os nossos dois distintos gêneros de percepções em relação ao seu grau de força e vividez, porque esse seria o único critério que pode ser imediatamente observado ou percebido em nossas mentes. Para que ele possa estabelecer como as impressões e as ideias se relacionam entre si relativamente ao seu caráter representativo (e assim prescrever uma distinção no que diz respeito ao que elas representam e ao modo como isso ocorre), ele precisa lançar mão de um raciocínio causal - tendo em vista que uma ideia apenas pode representar uma impressão, na medida em que a última for tida como a causa dessa representação ter ocorrido.

Muito embora o raciocínio que Hume empreende para estabelecer essa correspondência esteja baseado em observações empíricas acerca do que se passa na mente, se o critério primordial que nos permite distinguir impressões de ideias estivesse fundado, desde o início, unicamente no que elas podem representar, Hume enfrentaria dificuldades incontornáveis ao buscar efetuar a sua crítica ao fundamento racional da máxima causal (isto é, seria um tanto controverso se ele estabelecesse essa distinção, primordialmente, mediante um raciocínio causal e, posteriormente, pusesse em questão a máxima que, supostamente, assegura esse raciocínio). Por esse motivo, a nosso ver, ele precisa, inicialmente, de um critério de divisão 
entre nossas percepções que seja imediatamente percebido na mente (ainda que esse critério não seja suficiente).

Sobretudo, parece-nos bastante elucidativo o fato de que, mesmo quando Hume enfatizou que essa distinção reside apenas no grau de força e vividez com que uma e outra surgem na mente, ele ainda assim descreveu as ideias como sendo "pálidas imagens" das impressões (ou como "representando" as mesmas de um modo mais fraco). Consideramos que esse seja um dos indícios que apontam que o filósofo, desde o início de sua investigação, reconhecia que o critério de divisão entre as nossas percepções baseado tão somente no grau de força e vividez não era um critério suficiente.

Em um estudo bastante referenciado acerca dos distintos significados que podem ser encontrados para o termo "objeto" ao longo do Tratado, Marjorie Grene (1994) concluiu que, embora Hume muitas vezes faça alusão a uma impressão de sensação como tendo ou representando um objeto (o que pode sugerir que ele admite, já mesmo na parte teórica de sua filosofia, que existam objetos externos à mente, os quais são representados por essas impressões), ele não objetiva delinear essa alternativa.

Grene (1994, p. 167) sustenta que essas alusões ocorrem porque, como o próprio filósofo admite na seção "Do ceticismo quanto aos sentidos" (HUME, 2009), nós somos naturalmente coagidos a acreditar e, por consequência, a supor que os objetos corpóreos (independentes à mente) existem - e não porque as impressões, de fato, representam esses objetos. Vejamos como Hume inicia essa seção: "Podemos perfeitamente perguntar que causas nos induzem a crer na existência dos corpos. Mas é inútil perguntar se existem ou não corpos. Esse é um ponto que devemos dar por suposto em todos os nossos raciocínios" (HUME, 2009, p. 220, grifo do autor).

O que Hume busca efetuar nessa seção não é, portanto, provar que os objetos corpóreos, de fato, não existem (o que seria impossível, uma vez que ele parte tão somente de nossas percepções), mas sim mostrar que a noção de um objeto corpóreo, contínuo e independente à mente, é uma noção "ilusória" ou "fictícia" que não pode ser advinda nem dos sentidos, nem de nenhum raciocínio causal propriamente dito ${ }^{5}$. Infelizmente, uma análise mais pormenorizada

\footnotetext{
${ }^{5}$ Como não é nosso objetivo aqui explicitar os motivos de nossa crença na noção fictícia de um objeto corpóreo externo, contínuo e independente, não só porque fugiria muito de nossos propósitos atuais, como também porque exigiria outros aspectos da teoria cognitiva de Hume, por ora, aludimos a duas explicitativas afirmações do filósofo acerca desse ponto: "A suposição da existência contínua dos objetos ou percepções sensíveis não envolve
} 
dessa argumentação (acerca dos motivos que nos levam a essa crença fictícia) fugiria muito dos nossos propósitos atuais. Por ora, queremos apenas sublinhar que estamos de acordo com a conclusão de Marjorie Grene (1994, p. 169) de que as impressões de sensação não representam os objetos externos (ainda que nós suponhamos, na prática, exatamente isso). Acima de tudo, elas mesmas são os objetos com os quais mentalmente lidamos.

Não queremos sugerir, com isso, que Hume negue, de modo assertivo, a existência de objetos distintos de nossas impressões de sensação - simplesmente não podemos asserir, cognitivamente, nada acerca de suas propriedades, as quais, supostamente, não sejam as próprias propriedades de nossas impressões.

Uma vez que as únicas existências acerca das quais a nossa mente pode estar segura são as próprias percepções, nunca poderíamos observar uma conjunção constante entre as impressões e os objetos externos supostamente independentes, de modo a afirmarmos que entre eles há uma relação causal, como podemos observar uma tal conjunção entre as ideias e as impressões (porque aquela conjunção exigiria uma experiência de uma entidade ontologicamente distinta de nossas percepções) ${ }^{6}$.

Isto é, ainda que suponhamos a existência independente de objetos externos corpóreos, não podemos asserir, para fins cognitivos, se eles são as causas das nossas impressões simplesmente porque eles não são entidades mentais que possam ser percebidas. Consequentemente, as propriedades que supomos advir dos objetos externos nada mais são do que as propriedades de nossas próprias impressões de sensação.

contradição. Podemos facilmente ceder à nossa inclinação para tal suposição. Quando a exata semelhança de nossas percepções nos faz atribuir a elas uma identidade, podemos eliminar a aparente descontinuidade, fantasiando um ser contínuo, capaz de preencher esses intervalos e preservar uma identidade perfeita e integral em nossas percepções" (HUME, 2009, p. 241, grifo nosso)/ "Embora a propensão natural da imaginação nos leve a atribuir uma existência contínua a esses objetos ou percepções sensíveis que vemos assemelhar-se uns aos outros em sua aparição descontínua, um pouco de reflexão e filosofia basta, contudo, para nos fazer perceber a falácia dessa opinião. [...] quando comparamos experimentos e raciocinamos um pouco acerca deles, rapidamente percebemos que a doutrina da existência independente de nossas percepções sensíveis é contrária à mais clara experiência" (HUME, 2009, p. 243, grifo nosso).

${ }^{6}$ Nos termos de Hume: "Mas como os únicos seres que jamais [sic] estão presentes à mente são as percepções [But as no beings are ever present to the mind but perceptions], segue-se que podemos observar uma conjunção ou uma relação de causa e efeito entre diferentes percepções, mas nunca podemos observá-la entre percepções e objetos. Portanto, é impossível que, da existência ou de qualquer qualidade das percepções, possamos jamais formar uma conclusão concernente à existência dos objetos, e que jamais possamos satisfazer nossa razão acerca desse ponto" (HUME, 2009, p. 245). 
Uma vez que as únicas existências acerca das quais a nossa mente pode estar segura são as próprias percepções, nunca poderíamos observar uma conjunção constante entre as impressões e os objetos externos supostamente independentes, de modo a afirmarmos que entre eles há uma relação causal, como podemos observar uma tal conjunção entre as ideias e as impressões (porque aquela conjunção exigiria uma experiência de uma entidade ontologicamente distinta de nossas percepções).

Sobretudo, os sentidos não podem nos apresentar (mediante as impressões de sensação) nenhuma existência contínua e independente, distinta da de nossas próprias percepções. A ideia de uma existência distinta e contínua, Hume conclui, é advinda de determinadas qualidades de nossas impressões conjuntas com determinadas qualidades de nossa imaginação: algumas impressões se apresentam à mente de um modo mais constante e coerente (como se dependessem regularmente umas das outras) e é isso que nos leva a supor, causalmente, que algo deve servir de fundamento a essa coerência e constância (isto é, algo que exista contínua e independentemente). Mas essa inferência causal não é legítima, tendo em vista que nunca experienciamos esse algo e, por isso, nunca tivemos a ocasião de adquirir um hábito a respeito de sua suposta conjunção com a coerência observada entre nossas percepções, a qual nos permitisse assentir, causalmente, tal ideia.

Por ora, foquemos nossa atenção nas interpretações que, contrariamente à interpretação que estamos delineando, afirmam que as impressões de sensação podem representar os objetos externos. Por seu turno, Garret (2006, p. 22) argumenta que a intenção de Hume não é defender que as impressões de sensação sejam os únicos objetos, aos quais as nossas ideias se direcionam, mas sim que elas podem representar os objetos corpóreos.

Mas o modo como Garret caracteriza, no início de seu artigo, o que Hume entende por “corpo", de maneira a poder afirmar que uma impressão pode representá-lo, não nos parece ser distinto do que temos admitido até aqui. Vejamos:

Na verdade, a observação de Hume não implica que os corpos que são distintos das percepções da mente são inconcebíveis; implica apenas que não podemos concebê-los como sendo especificamente diferente de nossas ideias e impressões (GARRET, 2006, p. 7).

Kail (2007) afirma algo semelhante a Garret (2006) ao buscar defender uma posição realista de que os objetos externos se assemelham às nossas percepções: 
A diferença entre as percepções e objectos externos é apreendida em duas maneiras. Em primeiro lugar, tais objetos são como as percepções, exceto que eles têm 'diferentes relações, conexões e durações ': isto é, eles continuam a existir quando não são percebidos e são distintos. [...] Em segundo lugar, a noção de uma ideia relativa permite ao sujeito pensar que pode haver fatos sobre esses objetos para além dos representados na percepção pela [relação] de semelhança (KAIL, 2007, p. 60).

O ponto central dessas interpretações consiste em que Hume apenas não admite que as impressões representam objetos externos "especificamente" diferentes, em sua existência (e, portanto, poderia admitir que elas possam representar os objetos externos, se não os considerarmos como "especificamente" diferentes).

De modo geral, Hume argumenta que não podemos, legitimamente, conceber os objetos externos como tendo uma existência especificamente diferente da de nossas percepções e, por isso, o máximo que podemos fazer é formar uma ideia relativa, supondo, a partir dela, que esses objetos existem em relações, conexões e durações diferentes (sem, com isso, pretender compreender em que consistem essas diferenças).

Mas, como temos visto, na seção "Do ceticismo quanto aos sentidos", consideramos que Hume busca justamente explicitar como chegamos a crer, falaciosamente, nessa ideia relativa (de que os objetos externos existem contínua e independentemente). Ora, se não concebemos os objetos corpóreos como existindo de um modo especificamente diferente de nossas impressões, nem como tendo qualidades intrínsecas diferentes daquelas que são apresentadas por elas, em que sentido podemos afirmar, para fins unicamente teóricos, que as impressões podem representar esses objetos?

Certamente Hume considera importante que se preserve uma distinção entre os objetos corpóreos independentes da mente e as percepções. Entretanto, essa distinção é marcada pela questão acerca dos motivos que nos levam a atribuir a esses objetos, os quais supomos ter as mesmas características de nossas percepções, uma existência contínua e independente da mente.

Ora, se o filósofo declaradamente afirma que não podemos asserir, cognitivamente, a partir de nossas percepções, acerca da existência independente de objetos corpóreos e, por isso, não podemos fazer menção a nada que, supostamente, seja inerente a eles - consequentemente, apenas podemos investigar os motivos da nossa crença fictícia em sua existência contínua e independente -, não nos parece que uma leitura realista, a qual sustente que ele poderia admitir 
que as impressões de sensação representem os objetos corpóreos (cuja existência, especificamente, não difere da das nossas impressões), possa dar cabo da presente questão.

Apesar disso, não objetivamos sugerir que uma leitura realista (no sentido de que as impressões representam os objetos corpóreos) não seja inteiramente possível ou mesmo coerente. Apenas sublinhamos que, uma vez postas as limitações que Hume assinala, empiricamente, à noção de "corpo" (e que, como vimos, Garret e Kail as admitem), não faria diferença se atribuíssemos, na parte teórica de sua filosofia, as características de nossas impressões aos objetos corpóreos (entendidos como especificamente indistintos de nossas impressões) ou às próprias impressões. Isso porque não haveria como garantirmos que uma impressão x' representa, veridicamente, um objeto corpóreo x (ou uma de suas características), se não os concebemos como existindo de modos especificamente diferentes.

Como a nossa crença na existência contínua e independente desses objetos não nos leva a conceber nenhuma característica distinta daquelas que as nossas impressões de sensação nos apresentam, em termos humeanos, não faria diferença se afirmássemos a proposição “a impressão x representa o objeto corpóreo x" ou a proposição "a impressão x representa a impressão x" (a menos, claro, que pudéssemos dar uma prova da existência independente dos objetos corpóreos, o que Hume admite, desde o início, não ser possível, já que partimos unicamente de nossas percepções; ou que assumíssemos essa existência distinta desde o início, o que Hume não considera legítimo).

Assim, mesmo sem negar as interpretações de Garret (2006) e Kail (2007) diretamente, podemos pôr em questão qual seria o sentido em se afirmar que uma impressão representa um objeto corpóreo, na medida em que a existência desse objeto não difere especificamente da existência da mesma. Não estaríamos, de certo modo, também admitindo a possibilidade de que tal impressão esteja, originalmente, tão somente representando a si mesma? Poder-se-ia argumentar, contra a leitura que estamos delineando, que, se não há diferença entre aquelas duas proposições, seria bem mais verossímil à nossa experiência a afirmação de que as impressões representam os objetos externos.

Consideraremos brevemente uma elucidativa afirmação, proferida por A. J. Ayer (1963), a qual, a nosso ver, pode nos auxiliar a responder diretamente a essa objeção. Essa afirmação põe em questão justamente se o que está sendo objetado pode mesmo ser considerado 
como uma questão de fato, isto é, uma questão que possa ser decidida mediante dados empíricos, ou não:

[...] quando eu digo 'eu nunca vejo as coisas materiais, mas apenas dados sensíveis', estou dizendo algo cuja verdade ou falsidade não faz qualquer diferença para a natureza da minha experiência. [...] Porque, se nós nos permitimos dizer que a frase 'Eu nunca vejo as coisas materiais, mas apenas dados sensíveis' expressa tanto uma verdadeira como uma falsa proposição, sugerimos assim que [...] a sua validade depende de fatos empíricos. [...] [Mas] essa é uma questão de haver motivos alheios para se preferir um método de descrição em relação a outro, o qual é igualmente verdadeiro perante os fatos" (AYER, 1963, p. 27-28).

Para os nossos propósitos, poderíamos reformular o conteúdo dessa afirmação do seguinte modo: se a interpretação que estamos delineando e a interpretação de que as impressões representam os objetos externos não discordam em pontos cruciais (em específico, não discordam que não haja uma diferença específica relativamente à existência das impressões), então a questão a respeito de se as impressões representam, intencionalmente, esses objetos ou se elas mesmas são esses objetos em questão apenas pode ser decidida relativamente ao modo como se considera mais apropriado proferi-la - como temos defendido, a nosso ver, a segunda descrição é mais apropriada à teoria humeana. Simplesmente as impressões são os objetos sensíveis com os quais lidamos imediata e mentalmente, isto é, o material ou conteúdo bruto que os sentidos nos fornecem (o dado sensível ["the sense-data"]).

Qualquer asserção acerca da existência de objetos corpóreos independentes da mente sempre envolve algo que está para além do que os sentidos nos fornecem, a saber, os princípios da imaginação. Os objetos externos que supomos existir independentemente de nossas percepções e que, por isso, supomos ser as causas de nossas impressões de sensação são o efeito de uma crença advinda do modo como a nossa imaginação responde a uma sucessão de certas impressões, as quais apresentam uma constância peculiar.

\section{CONSIDERAÇÕES FINAIS}

Desse modo, apenas sublinhamos que o nosso intuito é sugerir que, na parte teórica da filosofia humeana, as ideias nada mais são do que as portadoras dos conteúdos que são imprimidos por nossas sensações (as "cópias" que representam, intencionalmente, esses conteúdos - isto é, uma ideia é sempre uma ideia "de" ou "sobre" algo), e que, por sua vez, os 
conteúdos de nossas impressões não são representativos, em sentido pleno (ou, se se prefere, em sentido semelhante ao das ideias), de nenhum objeto corpóreo externo.

nesse sentido, tais conteúdos são os próprios objetos primordiais com os quais lidamos (os objetos intencionais capazes de nos apresentar qualidades sensíveis particulares, aos quais as ideias se direcionam).

Em outros termos, as impressões de sensação não são intencionais, como as ideias: elas não se referem ou se direcionam a um outro conteúdo ou a um outro objeto, não são veículos que carregam informações sobre objetos, em sentido forte ${ }^{7}$. Na verdade, elas mesmas são esses objetos ou conteúdos sensíveis. Por fim, para concluirmos, é importante sublinhamos que Hume não descarta, positivamente, a alternativa de que possa haver algo, como um objeto corpóreo, ou mesmo algum poder, o qual, no fim das contas, realisticamente, cause essa coerência entre as percepções (a qual nos encaminha à crença em objetos externos independentes).

Hume apenas demarca que uma investigação acerca desse algo nos exigiria sair dos limites impostos por nossa experiência (isto é, exigiria uma especulação metafísica), na medida em que buscaríamos a causa última de nossas percepções mais originais. Nesse sentido, consideramos que, embora Hume conceba que possa haver algo que realmente exista independentemente de nossas percepções, ele é inteiramente cético em relação à prosperidade de uma investigação que, para fins cognitivos, busque explicitá-lo.

\section{REFERÊNCIAS}

ALLISON, Henry. Custom and Reason in Hume - A Kantian Reading of the First Book of the Treatise. New York: Oxford University Press, 2008.

AYER, Alfred J. The foundations of Empirical Knowledge. London: Macmillan \& Co, 1963.

BEEBEE, Helen. Hume on Causation. New York: Routledge, 2006.

BROUGHTON, Janet. Impressions and Ideas. In: TRAIGER, Saul (org.). The Blackwell
Guide to Hume's Treatise. Oxford: Blackwell Publishing, 2006.

DICKER, Georges. Hume's Epistemology and Metaphysics - An Introduction. New York: Routledge, 2001.

GARRET, Don. Cognition and Commitment in Hume's Philosophy. New York: Oxford University Press, 1997.

GARRET, Don. "Hume's Naturalistic Theory of Representation". Synthese, v. 3, n. 152, p. 201-219, 2006.

\footnotetext{
${ }^{7}$ A interpretação proposta no artigo descarta a suposição da coisa em si de Kant como causa dos objetos sensíveis ou fenômenos.
} 
KEMP SMITH, Norman. The Philosophy of

GARRET, Don. Hume's Theory of Ideas. In: RADCLIFFE, Elizabeth (org.). A Companion to Hume. Malden: Blackwell, 2008.

GRENE, Marjorie. The objects of Hume's Treatise. Hume Studies, v. 2, n. 20, p. 163167, 1994.

HUME, David. Tratado da natureza humana: uma tentativa de introduzir o método experimental de raciocínio nos assuntos morais. Trad. Déborah Danowski. São Paulo: Editora Unesp, 2009.

KAIL, P. J. E. Projection and Realism in Hume's Philosophy. New York: Oxford University Press, 2007.
David Hume - A Critical Study of its Origins and Central Doctrines. London: Macmillan and co, 1949.

NOONAN, Harold. Hume on Knowledge. New York: Routledge, 1999.

STROUD, Barry. Hume. London, New York: Routledge, 1977.

WAXMAN, Wayne. Hume's Theory of Consciousness. Cambridge: Cambridge University Press, 1994.

WRIGHT, John P. Hume's A Treatise of Human Nature. New York: Cambridge University Press, 2009.

PEREIRA, Rômulo Martins. As impressões de sensação representam os objetos externos?: considerações sobre o caráter representativo das percepções no Tratado da Natureza Humana. Complexitas - Rev. Fil. Tem., Belém, v. 1, n. 2, p. 24-37, jul./dez. 2016. Disponível em:< http://www.periodicos.ufpa.br/index.php/complexitas/article/view/3806>. Acesso em: 20 abr. 2017. 